\title{
La gestión del talento en la nueva economía
}

No me he podido resistir a incorporar el concepto de nueva economía en el título de este artículo. No he querido sustraerme al influjo de lo que está de moda, ni tampoco renegar de la pasión intrínseca a la condición de consultor que debe incorporar, más temprano que tarde, los nuevos conceptos, ideas y paradigmas a sus esquemas vitales, profesionales y de relación con el entorno.

La duda que me surge una vez compuesto el título del artículo es ésta: ¿estamos de verdad asistiendo al nacimiento de una nueva economía? Y si esto es así, ¿existen nuevos talentos a desarrollar desde las personas para favorecer el desarrollo de las nuevas organizaciones?

La principal preocupación que me surge es la de la inadecuada simplificación que se hace en muchos medios de ámbito económico haciendo coincidir el concepto de nueva economía con las start-ups y el mundo de Internet. Aunque no cabe duda que estos elementos constituyen una fuente notable de revolución en el mundo empresarial y económico, no constituyen los únicos elementos de transformación empresarial que están presentes en el concepto de nueva economía.

La Nueva Economía se caracteriza por una serie de rasgos esenciales, algunos de ellos favorecidos o potenciados por el uso de las nuevas tecnologías, que determinan la capacidad de competir de las organizaciones empresariales, entre las que podemos destacar las siguientes:

- La importancia del conocimiento y el talento como elementos de diferenciación frente a los competidores. Cada vez es más sencillo reproducir los elementos físicos de los negocios, por lo que las empresas exitosas están desarrollando mecanismos de incentivación de la generación, adquisición, almacenamiento, difusión y reutilización del conocimiento en el seno de sus organizaciones.
Sabin Azua es socio de KPMG

Consulting.

Contato: sazua@kpmg.es 
- El énfasis en la velocidad de cambio de las organizaciones para adaptarse a cambios en los mercados, en la introducción de nuevas tecnologías, nuevos productos o servicios etc., la adaptabilidad de los esquemas de gestión a un nivel acuciado de cambio va a ser una fuente importante de ventajas competitivas.

- Las empresas deben incorporar una cultura y una praxis de innovación. La creatividad, la capacidad de reinventar las operaciones de la empresa, constituirán una base sólida para crear valor en las organizaciones.

- Las estrategias de fidelización de los clientes va a constituir uno de los esfuerzos fundamentales de la organización. En un mundo en que como dicen los modernos "estamos a un clic de cambiar de proveedor", la articulación de estrategias ingeniosas de retención de clientes va a ser una necesidad importante para las organizaciones.

- La necesidad de establecer nuevos sistemas de medición de los resultados de las empresas y de sus procesos de creación de valor. Si es verdad que los activos intangibles constituyen los elementos fundamentales de capitalización de las empresas, será necesario definir procesos de medición y gestión del capital intelectual en las organizaciones.

- El nivel de conectividad de las empresas va a resultar determinante para establecer la capacidad de competir de las empresas. La necesidad de concentrarse en sus competencias esenciales para, en compañía de otros, poder atender a todas sus actividades, hace necesario la definición de nuevos esquemas organizativos abiertos que se complementen entre sí ("la constelación", "la empresa ampliada", "la red" etc.).

- El nivel de emprendizaje que adopten las organizaciones va a resultar determinante para favorecer su competitividad. La asunción de una cultura de riesgo, de aventura, va a estar cada vez más presente en los escenarios competitivos internacionales.

- La globalización de las actividades económicas no podía faltar a esta enumeración de elementos constituyentes de la nueva economía. Es necesario que las empresas alcancen un nivel importante de globalización de todas las actividades de su cadena de valor, pero manteniendo ó desarrollando la capacidad de articularlas localmente.

- La utilización de las nuevas tecnologías de la información facilitan la reinvención de todas las estrategias y procesos de las organizaciones. Asistimos a una profunda relación de las empresas con sus empleados, con sus clientes, con sus proveedores, con agentes relacionados etc., que pueden ser aprovechados para mejorar su competitividad.

- El compromiso de las personas con sus organizaciones, así como el nivel de seguridad en el empleo, se van haciendo cada vez menores. Es por ello que las empresas deben reenfocar sus estrategias de desarrollo 
profesional generando una mayor empleabilidad de las personas de su organización, tanto para su permanente adaptación a los cambios en su entorno laboral desde dentro de la empresa, como para su posible incorporación a otras organizaciones.

Si nos atenemos a los rasgos descritos previamente deberíamos concluir que es verdad que nos estamos incorporando a una nueva economía donde la conectividad entre todos los agentes involucrados es total, pero también es evidente que cada una de las organizaciones debe realizar un ejercicio permanente de contextualización para definir su futuro y el ámbito de relaciones que pretende establecer.

Las organizaciones de la nueva economía deberían ser, por tanto, unos entes profundamente dinámicos, en constante proceso de creatividad, innovación y adaptación al entorno, con una fuerte incidencia de los activos intangibles en los procesos de creación de valor, fuertemente apoyado en las capacidades individuales de sus miembros, sofisticadas tecnológicamente, dentro de un entorno favorecedor de la cooperación y del trabajo en equipo. Son organizaciones abiertas, revolucionarias que hagan del viejo principio de la revolución permanente su filosofía de vida.

En mi opinión, las organizaciones estáticas, con sistemas de gestión convencionales, altamente burocratizadas y jerarquizadas, sin pasión por los clientes y, con sistema de desarrollo de las personas tradicionales, están condenadas al ostracismo. No hay lugar en este nuevo mundo para las organizaciones poco creativas y poco conectadas con otras empresas.

Como sucede en todos los momentos históricos de profundas transformaciones sociales, culturales y económicas, estamos asistiendo al escenario de las grandes oportunidades y de las grandes amenazas. Aquellas organizaciones visionarias y emprendedoras serán las que tendrán las capacidades de asumir retos especiales que les hagan triunfar en el nuevo entorno competitivo.

En este marco debemos plantearnos cuales son los talentos requeridos para la nueva situación en la que se mueven las empresas. En este sentido se produce una esquizofrenia: las empresas deben adaptarse a los requerimientos de la nueva economía, pero manteniendo, simultáneamente, rasgos de gestión de los "viejos tiempos".

No es verdad que todo va a ser electrónico, no es verdad que las empresas triunfadoras van a ser las nacidas al amparo de la nueva situación, la mayor parte de las empresas que triunfarán en la nueva economía son las empresas que ya están triunfando en la vieja economía, si es que son capaces de acertar con la estrategia y el ritmo de renovación.

Lo que si ocurrirá es que las empresas nacidas al amparo de la nueva economía - las pioneras — van a transformar radicalmente los estándares de gestión de las empresas y las expectativas de los clientes. 
Es posible que muchas de ellas mueran (como ya empiezan a caer algunas) pero los clientes asumirán esos estándares como válidos y se los exigirán al resto de empresas.

Este escenario en el que nos movemos constituye el campo de batalla en el que deberán moverse las organizaciones en los próximos años. La necesidad de una gestión dual que contemple la reinvención de la empresa en el nuevo escenario, mientras atiende a sus clientes y a su realidad de gestión actual, va a forzar a las empresas a disponer de una gama de talentos (individuales y grupales) de amplio espectro, que articule el proceso de transformación de una manera sólida y rápida, en función de la rapidez de cambio de la rama de actividad en que se mueve.

¿Existen unos talentos en los que deberá sustentarse la persona - dentro de las organizaciones - para poder aportar su contribución a este proceso de transformación de las organizaciones de forma armónica? ¿Están las organizaciones preparadas para establecer marcos adecuados de convivencia para que estos talentos afloren de forma espontánea y coherente con las estrategias empresariales? ¿Existen mecanismos formales e informales de colaboración con otras organizaciones que posibiliten el desarrollo de esos talentos? ¿Tenemos líderes empresariales capaces de conducir los talentos de la organización hacia el éxito en la nueva economía?

Todas esas preguntas obsesionan a muchos directivos en nuestros días. Mi opinión personal es que la primera consideración que deben hacer los directivos es intentar definir algunos rasgos de la gestión de las personas de sus organizaciones para hacer frente a la necesidad de generar los talentos necesarios en este tipo de organizaciones.

Yo sigo pensando que el elemento de diferenciación de las empresas frente a sus principales competidores está y seguirá estando en el activo fundamental de las organizaciones: las capacidades inherentes a los individuos de la organización, en su habilidad para innovar, para crear y adquirir conocimiento, en la capacidad de articular un diálogo constructivo con los miembros de la propia organización y con todos y cada uno de los agentes relacionados, en la habilidad para tratar adecuadamente el ingente volumen de información y conocimiento disponible en la red (física y humana), en el aprovechamiento de las oportunidades emergentes, en una adecuada gestión del riesgo, en la compatibilización de pensamientos diferentes etc.

Considero que la adopción de mecanismos de gestión del capital intelectual, donde las empresas analizan los procesos de creación de valor a través de los activos intangibles, constituyen una buena fuente de identificación y potenciación de los talentos necesarios en las nuevas organizaciones: la identificación de los rasgos inspiradores del Capital Humano de la organización - sobre la base de las habilidades, conocimientos, actitudes de los individuos de la organización, su transformación en el Capital Estructural que representa talentos 
organizacionales (más perdurables en el tiempo) y, su posterior traslación a talentos de relacionabilidad con otros agentes, generan activos de conectividad con otras organizaciones que pueden medirse y gestionarse a través del Capital Relacional.

En ese proceso de reinvención de la empresa, los talentos de las personas de la organización deben ser el motor de transformación. La empresa debe generar marcos adecuados que permitan procesos innovadores de creación de conocimiento aplicado al negocio, la articulación de mecanismos de transmisión y difusión del conocimiento y la información disponible en la organización para facilitar la innovación en el seno de la empresa, la necesidad de configurar empresas abiertas (con múltiples relaciones con otras organizaciones) de forma que los trabajadores accedan a nuevos conocimientos y/o mecanismos de trabajo que fomenten la creatividad interna.

Aún cuando siempre se corre un riesgo de banalización de los contenidos al realizar generalizaciones, me gustaría señalar algunos talentos que, desde mi particular punto de vista, deberán potenciarse entre los individuos de las empresas de la nueva economía:

- La capacidad de innovación y anticipación. Uno de los talentos más apreciados en las empresas es la capacidad de los individuos de anticipar situaciones, adaptarse continuamente a los cambios de entorno y el mantenimiento de una posición inconformista en relación con todos las facetas de su actividad.

- La actitud emprendedora de las personas, implícita en una cultura de orientación al riesgo. La existencia de un cierto nivel de aventura, de búsqueda de nuevos caminos, de sentido exploratorio, deberá estar presente en los individuos de las organizaciones. No se pueden generar condiciones organizativas que mermen la capacidad de iniciativa y emprendizaje de los miembros de la organización.

- La adquisición de conocimientos versátiles y transversales al conjunto de la organización. Cada vez más, las capacidades de los individuos tendrán una aplicación más general en el seno de sus organizaciones.

- La facilidad para participar en un diálogo creador. Esto sólo será posible si las empresas asumen que la diversidad genética de sus miembros es una fuente real de creación de conocimiento. La construcción de nuevos horizontes para la organización solamente será viable desde la base de aportaciones de puntos de vista distintos, de experiencias vitales y profesionales dispares, de capacidades complementarias etc. Los directivos deben romper con su visión unitaria de las condiciones de los individuos, aprovechando la riqueza del pensamiento y la acción creadora de personas y/o grupos distintos.

- La necesidad de desarrollar la imaginación de los individuos de la organización. Este es uno de los talentos que menos se ejercitan en las 
organizaciones. Me gustaría citar al Profesor Johan Roos (de IMD y del Imagination Lab.): "Es en el momento en que jugamos cuando desarrollamos nuestra imaginación. Los directivos deben fomentar situaciones en sus organizaciones donde sus miembros, en un marco de mejora, jueguen seriamente para buscar soluciones imaginativas a su futuro y a su problemática específica".

- La necesidad de buscar personas que tengan una amplia visión global del mundo, no solamente en lo que hace referencia a mercados exteriores, sino en todos los elementos de gestión vinculados con su actividad, pero que sean capaces de aterrizar dicha visión en su entorno más inmediato, generando condiciones adecuadas para el desarrollo de los profesionales en su entorno local. El talento para combinar la globalización y la localización del pensamiento y de la acción van a ser determinantes en la definición de los buenos profesionales del futuro.

Todos estos rasgos señalados con anterioridad describen lo que puede considerarse un nuevo trabajador de la nueva economía que, en síntesis puede describirse como: "Un individuo dialogante y creador, constructor de ideas y de consensos, con aportación de su imaginación y su conocimiento al proyecto, comprometido con el proceso de creación de valor de la empresa, abierta al mundo y a las relaciones con cualquier agente con los que interactúe la empresa, en el uso adecuado de las posibilidades que brindan las nuevas tecnologías de la información".

El papel de las empresas de la nueva economía es desarrollar marcos de convivencia en el que estos talentos de los individuos de sus organizaciones se identifiquen, se relacionen adecuadamente con otros talentos de la organización y de otros agentes relacionados, se potencien mediante una adecuada gestión del conocimiento inherente a la organización $y$, tengan cauces claramente identificados de incorporación de ese conocimiento a los procesos básicos de negocio de la empresa donde se generen sus fuentes de diferenciación frente a los competidores. 


\section{Resumo}

\section{A gestão do talento na nova economia}

\section{Sabin Azua}

O artigo aborda a questão da gestão de talento nas empresas da nova economia, destacando que o papel dessas empresas é desenvolver marcos de convivência, com os quais o talento de seus funcionários possa se identificar e se relacionar adequadamente tanto com outros talentos da organização como com agentes externos, potencializando-se mutuamente mediante uma adequada gestão do conhecimento dentro da organização.

\section{La gestión del talento en la nueva economía}

\section{Sabin Azua}

El artículo aborda la questión de la gestión del talento en las empresas de la nueva economía, destacando que el papel de estas empresas es desarrollar marcos de convivência, con los quales el talento de sus empleados pueda identificarse e relacionarse adecuadamente tanto con otros talentos de la organización como con otros agentes externos, potencializandose mutuamente mediante una adecuada gestión del conocimiento dentro de la organización.

\section{Talent management in the New Economy}

\section{Sabin Azua}

The article deals with the question of the talent management in the New Economy companies, which role is creating an environment in which its talents may identify with and adequately relate to other talents, both internally and externally, aiming at a mutually beneficial potentialization that is based on adequate knowledge management within the organization. 